\title{
Associations between estrogen receptor genetic polymorphisms, smoking status, and prostate cancer risk: a case-control study in Japanese men
}

\author{
Xi Lu${ }^{1} \cdot$ Yuko Yamano ${ }^{2}$ Hiroyuki Takahashi ${ }^{3}$ Masahide Koda ${ }^{1}$. \\ Yuki Fujiwara $^{1} \cdot$ Aya Hisada $^{1} \cdot$ Wataru Miyazaki $^{1} \cdot$ Takahiko Katoh $^{1}$
}

Received: 1 April 2015/Accepted: 16 May 2015/Published online: 7 August 2015

(C) The Japanese Society for Hygiene 2015

\begin{abstract}
Objective Prostate cancer ( $\mathrm{PCa}$ ) is one of the major causes of death among men. Our study investigated the association of ESR1 and ESR2 genotypes with susceptibility to PCa in relation to smoking status in Japanese.

Method A case-control study was performed with 750 Japanese prostate cancer patients and 870 healthy controls. After age-matching in case-controls, 352 controls and 352 cases were enrolled in this study. By using logistic regression analysis, the different genotypes from ESR1 and ESR2 were analyzed according to case/control status.

Result ESR2 rs4986938 AG and AG + AA genotypes were associated with significantly decreased risk of $\mathrm{PCa}$ (AG: $\mathrm{OR}=0.68,95 \%$ CI $0.47-0.97, P<0.05$ and $\mathrm{AG}+\mathrm{AA}: \mathrm{OR}=0.67,95 \%$ CI $0.47-0.94, P<0.05$ ). However, there was no significant association between ESR1 rs2234693 and PCa risk. When patients were grouped according to smoking status, the ESR2 rs1256049 AA genotype $(\mathrm{OR}=0.48,95 \%$ CI $0.25-0.95, P<0.05)$ and ESR2 rs4986938 AG + AA genotype $(\mathrm{OR}=0.64$, $95 \%$ CI $0.41-1.00, \quad P<0.05)$ showed significantly decreased PCa risk in the ever-smoker group.

Conclusion Our results suggest that the estrogen receptor ESR2 has a very important function to predict $\mathrm{PCa}$ and that
\end{abstract}

$\mathrm{Xi} \mathrm{Lu}$

lucyk1984@hotmail.com

1 Department of Public Health, Faculty of Life Sciences, Kumamoto University, 1-1-1 Honjo, Chuo-Ku, Kumamoto 860-8556, Japan

2 Department of Hygiene and Preventive Medicine, Showa University School of Medicine, Tokyo, Japan

3 Department of Pathology, The Jikei University School of Medicine, Tokyo, Japan different SNPs have different predictive values. Smoking may influence estrogenic activity and may influence PCa together with the estrogen receptor.

Keywords Prostate cancer - Estrogen receptor . Polymorphism · Genetic association studies - Smoke

\section{Introduction}

Prostate cancer (PCa), also known as carcinoma of the prostate, is the development of cancer in the prostate, a gland in the male reproductive system [1]. The number of clinical cases has been increasing annually. In Japan, PCa deaths accounted for 3.5-4\% of the total cancer deaths and it is predicted that mortality will increase to $10 \%$ of the total cancer deaths, with more than 80,000 males suffering from PCa in 2020 [2].

One of the hypothesized risk factors of PCa is older age. Almost all prostate cancers are detected in men aged $>50$ years; asymptomatic patients are usually identified through screening programs and symptomatic individuals present at outpatient clinics. About $70 \%$ of deaths due to prostate cancer are observed in patients $\geq 75$ years old in the USA [3] and Japan [4].

Smoking is also a risk factor for PCa. An association with smoking could have a hormonal basis; male smokers were found to have elevated levels of circulating androsterone and testosterone, which may increase PCa risk or contribute to cancer progression [5]. Twenty-four prospective cohort studies showed increased risk of incident PCa for smokers [6], though five studies found no positive association between smoking and PCa incidence in Japan [7-11].

Although the roles of estrogen in the pathogenesis of $\mathrm{PCa}$ remains poorly understood, estrogens have been 
implicated in the stimulation of aberrant prostate growth, control of cell growth, and programmed cell death in $\mathrm{PCa}$ cells $[12,13]$. Despite the controversy surrounding the exact role of estrogens on the prostate epithelium, estrogens have been used in the treatment of PCa because of their growthinhibitory effects [14]. Sex steroids (estrogen and progesterone) could play a key pathophysiological role in the development PCa. The effects of estrogen are mediated by two estrogen receptors (ERs), the ER-1, and the ER-2 [14]. These belong to a superfamily of nuclear receptors that are ligand-dependent transactivators [15]. The ESR1 gene is located on chromosome $6 \mathrm{q} 25.1$ and the ESR2 gene is located on chromosome 14q23.1. The ESR1 gene intron 1 contains a single-nucleotide polymorphisms (SNPs) named the $P v u$ II (T/C) (rs2234693) [16]. The $5^{\prime}$ and $3^{\prime}$ regions of the ESR2 gene have two common SNPs: a silent $1082 \mathrm{G} / \mathrm{A}$ transition in exon 5 ( $R s a \mathrm{I}, \mathrm{rs} 1256049)$, and G/A exchange at nucleotide 1730 in the $3^{\prime}$ untranslated region in exon 8 (AluI, rs4986938) [17]. Both receptors have been detected in human prostate normal mucosa $[16,17]$. The ESR1 gene is expressed in the stroma and at low levels in basal epithelial cells of normal prostate [18, 19]; the ESR2 gene is highly expressed in the prostate epithelium, signifying a direct effect of estrogen on the prostate [20]. Imamov and Cheng's studies have shown antiproliferative and anti-invasion properties of estrogen acting through ERS2 [21, 22]. The correlation between PCa and estrogen receptors ESR1 and ESR2 according to smoking status is unclear.

We studied a common SNP (rs2234693) in the ESR1 gene and two in the ESR2 gene (rs1256049 and rs4986938). To the best of our knowledge, no study has reported the association of ESR1 and ESR2 genotypes with susceptibility to $\mathrm{PCa}$ in relation to age and smoking status in Japanese men.

\section{Materials and methods}

\section{Study subjects}

DNA samples were obtained from participants at Jikei University Hospital (Tokyo, Japan) and Mitsui Memorial Hospital (Tokyo, Japan), the ethical approval and informed consent of this study were obtained from all participants. Case subjects in this study were 750 men of Japanese ancestry who were diagnosed with histologically confirmed PCa at Jikei University Hospital from April 1, 2005 to December 31, 2006. Men of Japanese ancestry who were undergoing health screening at Mitsui Memorial Hospital during the same period were asked to participate as control subjects. Although a total of 870 subjects were included, due to the fact that age can have a great impact on prostate cancer, we selected an age-adjusted control group using the case group's average age. Thus, we enrolled 352 controls and 352 cases in this study. All subjects were classified into two groups according to smoking status by self-report: the "never" group composed of non-smokers and the "ever" group composed of both current smokers and ex-smokers.

The blood samples were collected during the protocol period before each procedure was performed. We stored buffy coats immediately after blood collection at $-80{ }^{\circ} \mathrm{C}$ until we isolated DNA for genotyping of all case patients and control subjects. The Ethic Review boards at both Miyazaki University and Kumamoto University approved this study on April 1, 2005 (approval number 180) and April 26, 2012 (approval number 209). All participants were given an explanation of the nature of this study.

\section{Genotyping}

Common SNPs in ESR1 (rs2234693: T $>$ C) and ESR2 (rs4986938: G>A, rs1256049: G>A) genes, previously associated with alteration in receptor expression were selected for the purpose of the current study. Pre-validated allelic discrimination TaqMan real-time PCR assays (Applied Biosystems, USA) were used for detection of the respective SNPs in ESR1 and ESR2 genes. The reaction solution $(9 \mu \mathrm{L})$ was placed into each well of a 48 -well reaction plate (the remainder of the reaction solution was used to prevent experimental errors), and $1 \mu \mathrm{L}$ of DNA sample or water control was added to each tube. DNA samples with homozygous ESR1 mutant T/T and ESR2 mutant $\mathrm{G} / \mathrm{G}$ were used as control samples in each array plate.

\section{Statistical analyses}

The Student's $t$ test and Chi-squared test were used to compare genotype and smoking status between the patients and control subjects. The Pearson's Chi-squared test was also used for evaluating the probability of Hardy-Weinberg equilibrium. Relative associations between the two groups were assessed by calculating odds ratios (ORs) from contingency tables. In logistic regression analysis, the OR with corresponding $95 \%$ confidence intervals (CI) were calculated. All statistical tests were based on two-tailed probability and $P$ values of $<0.05$ were considered to be significant. Statistical analyses were carried out using SPSS Ver. 20 (SPSS Inc., Chicago, IL).

\section{Results}

The general characteristics of the cases and the controls are shown in Table 1. This study involved 352 patients with pathologically confirmed PCa and 352 controls, aged from 
Table 1 Demographic characteristics of prostatic cancer cases and controls

\begin{tabular}{llll}
\hline Characteristics & Controls $N=352(\%)$ & Case $N=352(\%)$ & $P$ value \\
\hline $\begin{array}{l}\text { Age at reference (years) } \\
\leq 65(\%)\end{array}$ & $176(50.0 \%)$ & $180(51.1 \%)$ & \\
$\quad \geq 66(\%)$ & $176(50.0 \%)$ & $172(48.9 \%)$ & $0.76^{\mathrm{a}}$ \\
Smoking status & $113(32.1 \%)$ & $127(36.1 \%)$ & \\
$\quad$ Never & $239(67.9 \%)$ & $225(63.9 \%)$ & $0.27^{\mathrm{a}}$ \\
Ever & $69(19.6 \%)$ & $56(15.9 \%)$ & $0.14^{\mathrm{a}}$ \\
$\quad$ Current smoker & $170(48.3 \%)$ & $169(48.0 \%)$ & $0.47^{\mathrm{a}}$ \\
$\quad$ Ex-smoker & $65.0( \pm 6.5)$ & $65.0( \pm 6.5)$ & $0.98^{\mathrm{b}}$ \\
Mean age (years), mean $\pm \mathrm{SD}$ & & & \\
\hline
\end{tabular}

${ }^{\text {a }} P$ values were calculated form chi-square test

b $P$ values were calculated form $t$ test

\begin{tabular}{llll}
\hline Genotype & Control $N=352(\%)$ & Case $N=352(\%)$ & OR (95 \% CI) \\
\hline rs2234693 ESR1 & & & \\
TT (Ref) & $80(22.7 \%)$ & $67(19.0 \%)$ & 1.00 \\
CT & $175(49.7 \%)$ & $191(54.3 \%)$ & $1.08(0.77-1.52)$ \\
CC & $97(27.6 \%)$ & $94(26.7 \%)$ & $0.76(0.49-1.18)$ \\
CT + CC & $272(77.3 \%)$ & $285(81.0 \%)$ & $0.99(0.71-1.36)$ \\
rs1256049 ESR2 & & & 1.00 \\
GG (Ref) & $167(47.4 \%)$ & $185(52.6 \%)$ & $0.88(.64-1.20)$ \\
AG & $146(41.5 \%)$ & $25(7.1 \%)$ & $0.58(0.34-1.00)^{*}$ \\
AA & $39(11.1 \%)$ & $167(47.4 \%)$ & $0.82(0.61-1.10)$ \\
AG + AA & $185(52.6 \%)$ & & 1.00 \\
rs4986938 ESR2 & & $280(79.5 \%)$ & $0.68(0.47-0.97)^{*}$ \\
GG (Ref) & $254(72.1 \%)$ & $67(19.1 \%)$ & $0.57(0.18-1.76)$ \\
AG & $90(25.6 \%)$ & $5(1.4 \%)$ & $0.67(0.47-0.94)^{*}$ \\
AA & $8(2.3 \%)$ & $72(20.5 \%)$ & \\
AG + AA & $98(27.9 \%)$ & &
\end{tabular}

ORs were estimated using Chi-square statistic and multivariate logistic regression, respectively Ref reference group, $95 \%$ CI $95 \%$ confidence interval, OR odds ratio

$* P<0.05$

50 to 79 . The average ages of the case and control groups were both 65.0 years. No significant differences were observed between the cases and controls in terms of smoking status and pack-year status.

The genotype frequency distributions are shown in Table 2; SNP genotyping completion rates were $100 \%$. Hardy-Weinberg equilibrium was confirmed for the ESR1 rs2234693 genotype $(P=0.95)$, ESR2 rs1256049 genotype $(P=0.41), \quad$ and ESR2 rs4986938 genotype $(P=0.99)$ in the controls. For the ESR1 rs2234693 SNP, there were no statistically significant differences in risk for $\mathrm{PCa}$ between the case and control groups according to genotype. On the other hand, for the ESR2 rs1256049 SNP, the AA carriers showed decrease risk of $\mathrm{PCa}(\mathrm{OR}=0.58$, $95 \%$ CI $0.34-1.00, P<0.05)$. For the ESR2 rs4986938 SNP, AG and AG + GG genotypes also showed decrease risk of $\mathrm{PCa}(\mathrm{OR}=0.68,95 \% \mathrm{CI} 0.47-0.97, P<0.05$ and $\mathrm{OR}=0.67,95 \%$ CI $0.47-0.94, P<0.05$, respectively).

In order to check the PCa risk associated with genotypes in combination with smoking status, we classified all individuals in this study group as either never smokers or ever-smokers (Table 3). In the never-smoker group, there was no significant association between different genotypes and risk of PCa. In the ever-smoker group, the ESR2 rs1256049 AA genotype (OR $=0.48,95 \%$ CI 0.25-0.95, $P<0.05)$ and the ESR2 rs4986938 AG + AA genotype 
Table 3 Associations between the ESR1 and ESR2 genotype and prostatic cancer when stratified by smoking status

\begin{tabular}{|c|c|c|c|c|}
\hline Smoking status & Genotype & Control $N=113(\%)$ & Case $N=127(\%)$ & OR $(95 \% \mathrm{CI})$ \\
\hline \multirow[t]{13}{*}{ Never $(N=240)$} & \multicolumn{4}{|c|}{ rs2234693 ESR1 } \\
\hline & TT (Ref) & $31(27.4 \%)$ & $37(29.1 \%)$ & 1.00 \\
\hline & CT & $57(50.4 \%)$ & $63(49.6 \%)$ & $0.93(0.51-1.68)$ \\
\hline & $\mathrm{CC}$ & $25(22.1 \%)$ & $27(21.3 \%)$ & $0.91(0.44-1.87)$ \\
\hline & $\begin{array}{l}\mathrm{CT}+\mathrm{CC} \\
\text { rs1256049 ESR2 }\end{array}$ & $82(72.6 \%)$ & $90(70.9 \%)$ & $0.92(0.52-1.62)$ \\
\hline & GG (Ref) & $58(51.3 \%)$ & $68(53.5 \%)$ & 1.00 \\
\hline & AG & $45(39.8 \%)$ & $49(38.6 \%)$ & $0.93(0.54-1.59)$ \\
\hline & AA & $10(8.8 \%)$ & $10(7.9 \%)$ & $0.85(0.33-2.19)$ \\
\hline & $\mathrm{AG}+\mathrm{AA}$ & \multicolumn{3}{|c|}{ rs4986938 ESR2 } \\
\hline & \multicolumn{2}{|r|}{$78(69.0 \%)$} & $97(76.4 \%)$ & 1.00 \\
\hline & \multicolumn{2}{|r|}{$34(30.1 \%)$} & $28(22.0 \%)$ & $0.66(0.37-1.19)$ \\
\hline & \multicolumn{2}{|r|}{$1(0.9 \%)$} & $2(1.6 \%)$ & $1.61(0.14-18.07)$ \\
\hline & \multicolumn{2}{|r|}{$35(31.0 \%)$} & $30(23.6 \%)$ & $0.69(0.39-1.22)$ \\
\hline Smoking status & Genotype & Control $N=239(\%)$ & Case $N=225(\%)$ & OR $(95 \% \mathrm{CI})$ \\
\hline \multirow{15}{*}{$\begin{array}{l}\text { Ever } \\
(N=464)\end{array}$} & \multicolumn{2}{|c|}{ rs2234693 ESR1 } & & \\
\hline & TT (Ref) & $49(20.5 \%)$ & $30(13.3 \%)$ & 1.00 \\
\hline & CT & $118(49.4 \%)$ & $128(56.9 \%)$ & $1.17(0.77-1.77)$ \\
\hline & $\mathrm{CC}$ & $72(30.1 \%)$ & $67(29.8 \%)$ & $0.66(0.38-1.16)$ \\
\hline & \multirow{2}{*}{\multicolumn{2}{|c|}{$\begin{array}{l}\mathrm{CT}+\mathrm{CC} \quad 190(79.5 \%) \\
\text { rs } 1256049 \mathrm{ESR} 2\end{array}$}} & $195(86.7 \%)$ & $1.02(0.68-1.51)$ \\
\hline & & & & \\
\hline & GG (Ref) & $109(45.6 \%)$ & $117(52.0 \%)$ & 1.00 \\
\hline & AG & $101(42.3 \%)$ & $93(41.3 \%)$ & $0.86(0.58-1.26)$ \\
\hline & AA & $29(12.1 \%)$ & $15(6.7 \%)$ & $0.48(0.25-0.95)^{*}$ \\
\hline & \multirow{2}{*}{\multicolumn{2}{|c|}{$\begin{array}{l}\mathrm{AG}+\mathrm{AA} 130(54.4 \%) \\
\mathrm{rs} 4986938 \mathrm{ESR} 2\end{array}$}} & $108(48.0 \%)$ & $0.77(0.54-1.12)$ \\
\hline & & & & \\
\hline & GG (Ref) & $176(73.6)$ & $183(81.3 \%)$ & 1.00 \\
\hline & AG & $56(23.4 \%)$ & $39(17.3 \%)$ & $0.67(0.42-1.06)$ \\
\hline & AA & $7(2.9 \%)$ & $3(1.3 \%)$ & $0.41(0.11-1.62)$ \\
\hline & $\mathrm{AG}+\mathrm{AA}$ & $63(26.3 \%)$ & $42(18.6 \%)$ & $0.64(0.41-1.00)^{*}$ \\
\hline
\end{tabular}

ORs were estimated using Chi-square statistic and multivariate logistic regression, respectively Ref reference group, $95 \%$ CI $95 \%$ confidence interval, OR odds ratio $* P<0.05$

$(\mathrm{OR}=0.46,95 \% \mathrm{CI}, 0.41-1.00, P<0.05)$ were associated with significantly lower risk of PCa.

\section{Discussion}

In the last decade, a large number of studies have attempted to unravel the genetic basis of PCa. Evidence points to genetic factors, such as variations in genes involved in hormone pathways, as the key players in PCa development $[14,23]$. In this study, we investigated the associations between genetic polymorphisms of the ESR1 and ESR2 estrogen receptors, smoking status, and PCa risk in a casecontrol study in Japanese men.
Comparison of ESR1 rs2234693 genotype frequencies between the PCa patient and control groups did not show statistically significant differences. In previous studies, however, further subgroup analyses based on country suggested that ESR1 rs2234693 (C/T) may be associated with increased risk of $\mathrm{PCa}$ among Indian and Iranian populations (ORs ranging from 1.93 to 4.46) [14, 24]. Another study failed to confirm these findings among American or Japanese populations [25] and our findings are consistent with this study.

Regarding the ESR2 rs1256049, those with the AA genotype had significantly reduced risk for PCa. Chen et al. reported that the ESR2 rs1256049 was not associated with $\mathrm{PCa}$ risk in either all subjects (Prostate Cancer Cohort 
Consortium) or only Caucasians [26], but to our knowledge, there were no data regarding the ESR2 rs1256049 SNP and PCa in Japanese men. Another finding of this study was a significant association between ESR2 rs4986938 and PCa; men with ESR2 rs4986938 AG and $\mathrm{AG}+\mathrm{AA}$ genotypes were less likely to have PCa. Although no significant association was observed for the AA genotype, there was a trend towards decreased chance of having $\mathrm{PCa}$, which is consistent with some previous studies [24, 27-30].

Bergner et al. tested the ESR1 and ESR2 genes in two human PCa cell lines. In their study, polymorphisms were found in both ESR1 and ESR2 genes and these may contribute to the genetic factors that influence the risk for developing PCa [31]. In another study, the author reported that high intake of phytoestrogens substantially reduced PCa risk among men with specific polymorphic variation in the promoter region of the ESR2 gene [32]. In a large population-based case-control study (1415 cases and 801 controls), 28 SNPs spanning the entire ESR2 gene were evaluated [33]. There was a statistically significant difference in allele frequency between cases and controls only for one of the typed htSNPs (rs2987983). Different ESR1 and ESR2 genotypes may exert their effects on PCa via different serum levels of reproductive hormones. Both androgens and estrogens play significant roles in the prostate. Specifically, it is a balance between their actions that is critically important in maintaining normal prostate growth [14]. All of these experimental studies and our results suggest that the ESR1 and ESR2 genetic polymorphisms examined in this study have functional significance, and thus modulate PCa risk.

In terms of smoking status, there was no significant difference observed between the cases and the controls in terms of smoking status $(P=0.37)$ and we also found no significant association between different genotypes in the never-smoker group. In the ever-smoker group, however, the ESR2 rs1256049 AA genotype and the ESR2 rs4986938 AG + AA genotype carriers showed significantly decreased PCa risk. Our findings agree with a study by Takamura et al. [34], which demonstrated that smoking may influence estrogenic activity and that these two factors may influence PCa together. Dai et al. found an association with smoking could also have a hormonal basis. Male smokers were found to have elevated levels of circulating androsterone and testosterone, which may increase $\mathrm{PCa}$ risk or contribute to cancer progression [5]; however, they did not report on the possible interaction between smoking and ESR genotype.

In interpreting the results of the current study, some limitations need to be addressed. First, the sample size was relatively small and may not provide sufficient power to estimate the association between gene polymorphisms and prostate cancer risk. Second, we did not account for the potential effects of diet in our study; for instance, some studies have reported that high intake of isoflavone, which is mainly found in soybeans and soy products, may reduce the risk of PCa. Third, all subjects were classified into either the "never" group, composed of non-smokers, or the "ever" group, composed of both current smokers and exsmokers; thus, we could not analyze the impact of smoking burden in terms of either the number of cigarettes smoked or pack-years. In spite of these limitations, our study still had some merits and values. To the best of our knowledge, this is the first study to analyze the relationship between estrogen receptor gene polymorphisms, smoking status, and PCa risk in Japanese men.

In summary, our results demonstrated that the ESR2 rs1256049 and rs4986938 genotypes, but not ESR1 rs2234693 genotype, had significant associations with risk for PCa in Japanese men. Our findings suggest that estrogen receptor genotype may be an independent risk factor for $\mathrm{PCa}$ and may also play a modulatory role in the metabolism of tobacco smoke components. The genotypes of estrogen receptor SNPs may differentially predict PCa risk.

Conflict of interests The authors have declared that no competing interests exist.

\section{References}

1. Prostate Cancer Treatment $\left(\mathrm{PDQ}^{\circledR}\right)$. National Cancer Institute. 2014. http://www.cancer.gov/types/prostate/patient/prostate-treat ment-pdq. Accessed 1 July 2014.

2. Hotoribe S. Your medicine book, a prostatic cancer. (in Japanese). Japan: Seibundo Shinnosha; 2008.

3. Hankey BF, Feuer EJ, Clegg LX, Hayes RB, Legler JM, Prorok $\mathrm{PC}$, et al. Cancer surveillance series: interpreting trends in prostate cancer-part I: Evidence of the effects of screening in recent prostate cancer incidence, mortality, and survival rates. J Natl Cancer Inst. 1999;91:1017-24.

4. Breslow N, Chan CW, Dhom G, Drury RA, Franks LM, Gellei B, et al. Latent carcinoma of prostate at autopsy in seven areas. The International Agency for Research on Cancer, Lyons, France. Int J Cancer. 1977;20:680-8.

5. Dai WS, Gutai JP, Kuller LH, Cauley JA. Cigarette smoking and serum sex hormones in men. Am J Epidemiol. 1988;128:796-805.

6. Huncharek M, Haddock KS, Reid R, Kupelnick B. Smoking as a risk factor for prostate cancer: a meta-analysis of 24 prospective cohort studies. Am J Public Health. 2010;100(4):693.

7. Allen NE, Sauvaget C, Roddam AW, Appleby P, Nagano J, Suzuki G, et al. A prospective study of diet and prostate cancer in Japanese men. Cancer Causes Control. 2004;15:911-20.

8. Mishina T, Watanabe H, Araki H, Nakao M. Epidemiological study of prostatic cancer by matched-pair analysis. Prostate. $1985 ; 6: 423-36$.

9. Nakata S, Imai K, Yamanaka H. Study of risk factors for prostatic cancer. (in Japanese). Hinyokika Kiyo. 1993;39:1017-24 (discussion 1024-5).

10. Oishi K, Okada K, Yoshida O, Yamabe H, Ohno Y, Hayes RB, et al. Case-control study of prostatic cancer in Kyoto, Japan: 
demographic and some lifestyle risk factors. Prostate. 1989;14: $117-22$.

11. Furuya $\mathrm{Y}$, Akimoto $\mathrm{S}$, Akakura $\mathrm{K}$, et al. Smoking and obesity in relation to the etiology and disease progression of prostate cancer in Japan. Int J Urol. 1998;5:134-7.

12. Bosland MC, Ford H, Horton L. Induction at high incidence of ductal prostate adenocarcinomas in NBL/Cr and Sprague-Dawley Hsd: SD rats treated with a combination of testosterone and estradiol-17 b or diethylstilbestrol. Carcinogenesis. 1995;16: 1311-7.

13. Robertson CN, Roberson KM, Padilla GM, O'Brien ET, Cook JM, Kim CS, et al. Induction of apoptosis by diethylstilbestrol in hormone-insensitive prostate cancer cells. J Natl Cancer Inst. 1996;88:908-17.

14. Safarinejad MR, Safarinejad S, Shafiei N, Safarinejad S. Estrogen receptors alpha (rs2234693 and rs9340799), and beta (rs4986938 and rs 1256049) genes polymorphism in prostate cancer: evidence for association with risk and histopathological tumor characteristics in Iranian men. Mol Carcinog. 2012;51:104-17.

15. Kuiper GG, Gustafsson JA. The novel estrogen receptor- $\beta$ subtype: potential role in the cell- and promoter-specific actions of estrogens and anti-estrogens. FEBS Lett. 1997;410:87-90.

16. Alessio AM, Hoehr NF, Siqueira LH, Ozelo MC, de Padua Mansur A, Annichino-Bizzacchi JM. Association between estrogen receptor alpha and beta gene polymorphisms and deep vein thrombosis. Thromb Res. 2007;120:639-45.

17. Rosenkranz K, Hinney A, Ziegler A, Hermann H, Fichter M, Mayer $\mathrm{H}$, et al. Systematic mutation screening of the estrogen receptor beta gene in probands of different weight extremes: identification of several genetic variants. J Clin Endocrinol Metab. 1998;83:4524-7.

18. Ehara H, Koji T, Deguchi T, Yoshii A, Nakano M, Nakane PK, et al. Expression of estrogen receptor in diseased human prostate assessed by non-radioactive in situ hybridization and immunohistochemistry. Prostate. 1995;27:304-13.

19. Bonkhoff H, Fixemer T, Hunsicker I, Remberg K. Estrogen receptor expression in prostate cancer and premalignant prostatic lesions. Am J Pathol. 1999;155:641-7.

20. Taylor AH, Al-Azzawi F. Immunolocalisation of oestrogen receptor $\beta$ in human tissues. J Mol Endocrinol. 2000;24:145-55.

21. Imamov O, Morani A, Shim GJ, Omoto Y, Thulin-Andersson C, Warner $\mathrm{M}$, et al. Estrogen receptor beta regulates epithelial cellular differentiation in the mouse ventral prostate. Proc Natl Acad Sci USA. 2004;101:9375-80.

22. Cheng J, Lee EJ, Madison LD, Lazennec G. Expression of estrogen receptor $\beta$ in prostate carcinoma cells inhibits invasion and proliferation and triggers apoptosis. FEBS Lett. 2004;566: 169-72.
23. Wang YM, Liu ZW, Guo JB, Wang XF, Zhao XX, Zheng X. ESR1 gene polymorphisms and prostate cancer risk: a HuGE review and meta-analysis. PLoS One. 2013;8(6):e66999.

24. Latil A, Bieche I, Vidaud D, Lidereau R, Berthon P, Cussenot O, et al. Evaluation of androgen, estrogen (ER $\alpha$ and ER $\beta$ ), and progesterone receptor expression in human prostate cancer by real-time quantitative reverse transcription-polymerase chain reaction assays. Cancer Res. 2001;61:1919-26.

25. Tanaka Y, Sasaki M, Kaneuchi M, Shiina H, Igawa M, Dahiya R. Polymorphisms of estrogen receptor a in prostate cancer. Mol Carcinog. 2003;37:202-8.

26. Chen YC, Kraft P, Bretsky P, Ketkar S, Hunter DJ, Albanes D, et al. Sequence variants of estrogen receptor $\beta$ and risk of prostate cancer in the National Cancer Institute Breast and Prostate Cancer Cohort Consortium. Cancer Epidemiol Biomarkers Prev. 2007;16:1973-81.

27. Suzuki K, Nakazato H, Matsui H, Koike H, Okugi H, Kashiwagi $\mathrm{B}$, et al. Genetic polymorphisms of estrogen receptor alpha, CYP19, catechol- $O$-methyltransferase are associated with familial prostate carcinoma risk in a Japanese population. Cancer. 2003;98:1411-6.

28. Risbridger G, Wang H, Young P, Kurita T, Wang YZ, Lubahn D, et al. Evidence that epithelial and mesenchymal estrogen receptor- $\alpha$ mediates effects of estrogen on prostatic epithelium. Dev Biol. 2001;229:432-42.

29. Bosland MC. The role of steroid hormones in prostate carcinogenesis. J Natl Cancer Inst Monogr. 2000;27:39-66.

30. Horvath LG, Henshall SM, Lee CS, Head DR, Quinn DI, Makela $\mathrm{S}$, et al. Frequent loss of estrogen receptor-beta expression in prostate cancer. Cancer Res. 2001;61:5331-5.

31. Bergner CC, Krause FS, Zugor V, Rith T, Schrott KM, Endele S, et al. Polymorphisms of human estrogen receptor. (ER) gene alpha and beta in prostate cancer PC-. EW and PC-OR cell lines. Anticancer Res. 2007;27:2071-4.

32. Hedelin M, Balter KA, Chang ET, Bellocco R, Klint A, Johansson JE, et al. Dietary intake of phytoestrogens, estrogen receptor-beta polymorphisms and the risk of prostate cancer. Prostate. 2006;66:1512-20.

33. Thellenberg-Karlsson C, Lindstrom S, Malmer B, Wiklund F, Augustsson-Balter K, Adami HO, et al. Estrogen receptor beta polymorphism is associated with prostate cancer risk. Clin Cancer Res. 2006;12:1936-41.

34. Takamura-Enya T, Ishihara J, Tahara S, Goto S, Totsuka Y, Sugimura T, Wakabayashi K. Analysis of estrogenic activity of foodstuffs and cigarette smoke condensates using a yeast estrogen screening method. Food Chem Toxicol. 2003;41:543-50. 